\title{
Revised Community of Inquiry as a Theoretical Foundation for understanding Students' Blended Learning Experiences
}

\author{
Sangeeth Ramalingam ${ }^{1 *}$, Harwati Hashim ${ }^{2}$, and Melor Md Yunus ${ }^{3}$ \\ ${ }^{1}$ Kolej Poly Tech Mara \\ ${ }^{1,2,3}$ Universiti Kebangsaan Malaysia \\ *Corresponding author.Email: harwati@ukm.edu.my
}

\begin{abstract}
Industrial Revolution 4.0 (IR4.0) is one of the buzzwords that changed many facets of a human being's life. Great emphasis is placed on the revolution in industries including education sector due to IR4.0. IR4.0 provides the opportunity to integrate more technology and innovation in teaching and learning process particularly during this pandemic of Covid-19. As a result of technology integration, myriad ways of teaching and learning were introduced such as machine learning, futuristic learning and the most common approach was blended learning. Blended learning is a form of educational technology which integrates both face to face and web-based learning. This approach is employed widely in many higher learning institutions, nevertheless very less research focused on the theoretical foundations for learners' blended learning experiences. The purpose of this paper is to propose Revised Community of Inquiry as a theoretical foundation for understanding blended learning experiences of students. Revised Community of Inquiry is one of the frameworks evolved based on socio-constructivism theory for blended learning and it focuses on teamwork and interaction in learning environment. Main discussion of this paper is related to Revised Community of Inquiry framework and how it can be employed in educational setting to examine students' blended learning experiences. The paper ends with recommendation of possible research avenues for prospective researchers.
\end{abstract}

Keywords: Blended Learning, Community of Inquiry, Revised Community of Inquiry, Theoretical framework

\section{CONCEPT OF BLENDED LEARNING}

Based on a broad perspective, blended learning can be understood as an approach which integrates face to face instruction and individual as well as group online learning. [1] defined blended learning as a language program that integrates both the elements of face to face and online with the suitable utilisation of technology. Blended instruction promotes the incorporation of media and technology in online learning environment [2]. Many different technologies and tools are used in blended learning classroom for the purpose of teaching and learning such as podcasts, wikis, blogs and so on.

The concept of blended learning evolved whereby learning is integrated with mobile technology starting from 2013. Teaching and learning process is conducted through the use of mobile technology. Many online platforms were emerged in blended learning such as MOOCs and also other web based tools due to the extended development of technologies. Various synchronous and asynchronous web-based tools were employed in blended learning classroom to facilitate conventional approach as well as to make the the whole teaching and learning process interactive. [3] stressed that blended learning is an innovative approach which acknowledges the benefits of both traditional learning and online learning. Therefore, the learners of blended learning classroom would obtain the advantages by involving in face to face activities as well as the elearning individual or group activities.

\section{CHARACTERISTICS OF WEB-BASED BLENDED LEARNING}

The significant criterion of web-based blended learning is both face to face instruction and online instruction are seamlessly integrated so that it can increase learners' engagement and therefore it can provide meaningful learning experiences to the students. Face to face instruction happens in a conventional classroom whereas online learning happens when there is an integration of technology in the learning process. Based on [4], blended learning is a pedagogical method which emphasizes on socialization from the 
conventional classroom and technologically driven learning possibilities from the online environment. Various face to face learning activities together with the synchronous and asynchronous online activities promote high level of students' engagement among the learners.

Blended learning instruction could not be developed and designed with rigid teaching and learning strategies as a traditional instruction. According to [5], blended learning must be carefully conducted with the awareness of adjustable design possibilities. This is because learners are unique, distinctive and they learn in different ways. Generally, students learn an information visually, auditorily, and by involving in activities (kinaesthetic). Thus, teaching and learning strategies for blended learning instruction should be carefully designed by considering the type of learners in classroom.

Another characteristic of blended learning is it is not simply combining or integrating face to face instruction with web-based learning, but it is beyond that. A good result of a blended learning instruction is from the learning environment whereby the face-to-face learning is incorporated with the appropriate use of technology to increase the learner engagement and flexibility. Thus, several crucial factors need to be considered for the implementation of blended learning such as the content, context and the appropriateness of the technology used. [6] stated few other factors for the blended learning instruction. Among the considerations that they have suggested are learning objectives and goals, situational demand, and instructors' experience. All these important aspects are need to be given thought to ensure successful blended learning instruction in classroom.

There is no specific pedagogy for blended learning. Nevertheless, it is very much associated with social learning theories such as socio constructivism, engagement theory, and cognitive theory. Thus, blended learning instruction focuses more on teaching and learning activities which promote high student engagement, flexibility, good social interaction, and collaboration. [7] stated students' independent learning experience is enhanced where the chances for teamwork have existed. This indicated that students' involvement in either face-to-face or online activities assist them to increase their independent learning skill and be flexible in their learning process.

\section{BENEFITS OF BLENDED LEARNING}

Face-to-face instruction combined with synchronous and asynchronous web-based technologies encourage learner engagement. Students can benefit a lot from blended learning instruction as they can learn at their own pace. When students participate in blended learning, they can personalize their own learning process. [8] stated that once the students can identify their learning style, they can choose the suitable materials or tools that work best for them in their learning process. This is how blended learning assists the students to personalize their own way of learning information.
[9] conducted a study on students' perspectives towards blended learning. The findings from the research revealed that students' involvement in blended learning instruction allows them to be highly responsible for their own learning and thus increase their learner engagement. In another study done by Donnie [10], it was highlighted that students' engagement level is increased when they participate in online collaborative tasks in blended learning environment. Learners' engagement in blended learning environment is also associated with their academic performance. This has been revealed in the studies conducted by [11];[12]; [13]. Among all methods, blended learning is considered as an appropriate approach for increasing learners' engagement [14].

Apart from increasing student engagement, blended learning instruction can be extremely convenient to the learners. This is because blended learning allows the students to review the lecture materials either in the version of document or video in case if the students missed any lesson. Recorded video of lecture will be uploaded in any suitable platform and available for the students. It is also very beneficial for the other students to do revision of a lecture as they can view the videos as many times they prefer.

Furthermore, blended learning instruction allows face-to-face instruction to be more effective and efficient as there is an integration of technology. Incorporation of an appropriate technology into face-toface instruction makes the whole process of teaching and learning to be more interactive and engaging. Besides, integration of technology also assists to reduce the passiveness level of the students in face-to-face classroom. Students who tend to be passive in face-toface classroom will be very active in online classroom. This is because students who are inactive in conventional classroom would feel very comfortable and confident in online activities particularly during the asynchronous tasks.

Implementation of blended learning does not give benefits to learners only, but it can be benefit to the instructors too. Blended learning instruction is very helpful for the instructors in terms of assessment. Variety assessment methods can be applied by the instructors in online environment particularly diagnostic and formative tests. According to [15], blended learning instruction provides the opportunity to the instructors to employ more reliable assessment methods. Diagnostic and formative assessments can be done while online learning takes place to evaluate the students' progress and to provide suggestions on how to improvise the students' academic performance. It is not necessary for the instructors to wait until the learning process is finished to evaluate the students.

\section{REVISED COMMUNITY OF INQUIRY}

Revised Community of Inquiry is evolved from Garrison and Vaughan's Community of Inquiry (CoI). Significant elements and characteristics of this Community of Inquiry made this as a suitable 
framework for investigating students' blended learning experiences. Community of Inquiry is considered as the heart of investigation by Garrison and Vaughan to examine students' higher education experiences particularly in blended learning environment. The three significant characteristics of Community of Inquiry are open, purposeful and discipline. The first characteristic of this model which is 'open' enables the participants to explore their opinions and views with freedom to construct meanings. Next characteristic is purposeful which means the whole Community of Inquiry is meaningful as it depends on maintained communication. The third criterion of this model which is discipline associated to the participants. Purposeful blended learning highly depends on the participants' discipline in the community during the interaction with the others.

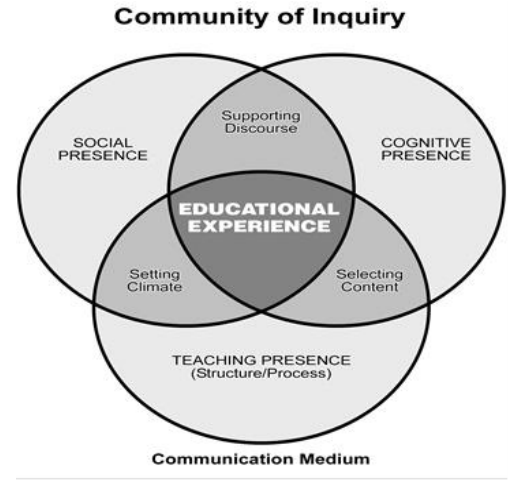

Figure 1 Community of Inquiry (CoI)

Figure 1 indicates the model of Community of Inquiry. The three important components of Community of Inquiry are social presence, cognitive presence and teaching presence. All these components are very crucial for successful blended learning instruction. Social presence is the skill of the participants to converse meaningfully in a trusted environment and to enhance their inter-personal communication through the method of demonstrating their personal traits [16]. Students must be able to express their views and opinions freely so that they have the sense of belonging to the community. Learners can involve in a purposeful communication process when they are able to express themselves by providing their viewpoints and thus the community is well established. Social presence enables the students to have a sense of responsibility and commitment towards the entire community of inquiry.

According to [16], cognitive presence is the extent to which learners are able to construct and confirm meaning through sustainable reflection and discourse. Sense of puzzlement, information exchange, connecting ideas and application of new ideas are the processes which occur repetitively in this element. Students are expected to accentuate more on exploration then integrate and finally apply ideas and solutions. Cognitive presence is considered as an extremely essential element of this model as community could contribute to the cognitive development of the learners.

Teaching presence is related to designing, facilitating, and directing cognitive and social processes for the purpose of learning outcomes achievement [16]. Teacher presence has a very crucial role for a sustainable and productive community of inquiry. This also serves as a medium to bring both social and cognitive presence together, apart from providing the importance to the curriculum, techniques and tasks. Teaching presence is very challenging especially in blended learning environment as this involves face to face instruction and web-based instruction.

All the three elements of Community of Inquiry (social presence, cognitive presence and teaching presence) assist to provide a comprehensive understanding on the students' blended learning experiences other than serving as a guidelines to design actual and engaging learning experiences. [17] proposed a new element to be included in the Community of Inquiry model which is learner presence and the framework is called as Revised Community of Inquiry. Learners' self-regulation is identified as a skill which is closely associated with the other three presences through the studies conducted by [17]. Self-regulation is one's own effort to select personal objective, identify the suitable methods and to implement the strategies [18]. Learner presence is considered very crucial as the students involved in autonomous learning process in blended environment. During autonomous learning, students find related materials, choose relevant questions and share those questions with their peers so that they can collaborate together to complete the provided tasks.

It is very crucial for the learners to have selfregulation skill as blended learning is a combination of face-to-face instruction and web-based learning [19]. [20] described self-regulation as self-generated process which means self-directed viewpoints, feelings and behaviour in attaining an objective. Students in blended learning environment need a high level of selfregulation skill. This is because they need to observe and monitor their management, manage their learning environment and take control over their communication process with the other classmates to enhance their learning [17]. [21] have identified three indicators for self-regulation namely forethought and planning, monitoring and strategy use. It is a paramount of importance for the students in a blended learning environment to plan and set personal goals, monitor and observe own progress and choose the suitable learning strategies [21]. The element of learner presence in Community of Inquiry allows the stakeholders of an institution to understand and to comprehend students' blended learning experience in a detailed manner. Figure 2 depicts Revised Community of Inquiry. 


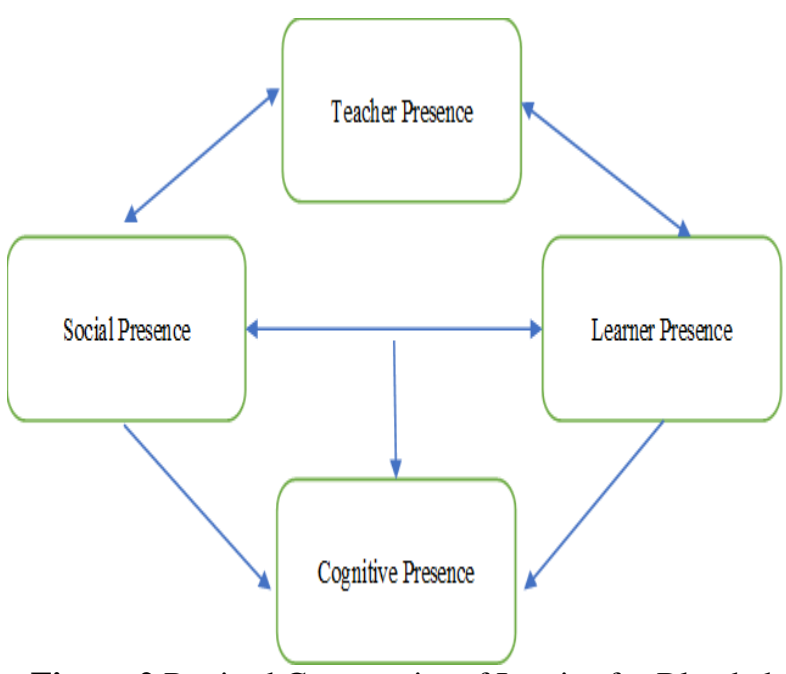

Figure 2 Revised Community of Inquiry for Blended Learning

Based on Figure 2, all the three components of Community of Inquiry which are social presence, cognitive presence and teacher presence are inter-related to each other. Both teacher presence and social presence are connected to learner presence. As illustrated in Figure 2, social presence is functioning as a mediating component which provides the context for the blended learning educational process. Teacher presence is very crucial in Revised Community of Inquiry as the teacher needs to ensure the entire learning process is meaningful and purposeful. The connection between cognitive presence and teaching presence becomes clear, after the learners are engaged with the tasks and practices. On top of that, teacher presence has a direct influence towards students' learning process after the learner engagement is achieved.

\section{CONCLUSION}

This paper has discussed the concept of blended learning as an educational approach. Students at this current age are very well equipped with digital tools and gadget for the purpose of education. Therefore, different technologies and tools are utilised for the purpose of teaching and learning in blended environment. This paper further discussed the characteristics of web-based learning. Even though there are many different types of web-based technologies, educators at higher level institutions should be able to identify the suitable technologies which can meet the learners' needs and match the learning outcomes.

Benefits of blended learning also has been explained in this paper. Both learners and educators benefit a lot by employing blended learning approach in classroom. Nevertheless, a careful consideration needs to be provided to the selection of relevant blended learning teaching and learning activities to meet the learning objectives of lessons. Lastly, the framework of Revised Community of Inquiry is discussed in terms of the four important components (social presence, cognitive presence, teacher presence and learner presence). The relevance of all these four components to community of inquiry made this framework appropriate to be implemented to examine the blended learning experiences among the students. Therefore, future blended learning studies could focus on employing Revised Community of Inquiry in order to investigate students' learning experiences in classroom.

\section{AUTHORS' CONTRIBUTIONS}

All authors have made a significant contribution to the work.

\section{ACKNOWLEDGMENT}

This work was supported by Universiti Kebangsaan Malaysia [GG-2019-006] and [GG-2020-014].

\section{REFERENCES}

[1] P. Sharma and B. Barrett, Blended Learning: Using technology in and beyond the language classroom. England: Macmillan Publishers Ltd, 2007.

[2] P. Sharma, "Blended learning," ELT J., vol. 64, no. 4, pp. 456-458, 2010, doi: 10.1093/elt/ccq043.

[3] D. Lalima and K. Lata Dangwal, "Blended Learning: An Innovative Approach," Univers. J. Educ. Res., vol. 5, no. 1, pp. 129-136, 2017, doi: 10.13189/ujer.2017.050116.

[4] C. D. Dziuban, J. L. Hartman, and P. D. Moskal, "Blended learning," Educ. Cent. Appl. Res., vol. 2004, no. 7, pp. 1-12, 2004, doi: 10.1136/bmj.330.7495.829.

[5] D. R. Garrison and N. D. Vaughans, "Blended Learning in Higher Education:Framework,Principles, and Guidelines," John Wiley \& Sons, INc, 2008, pp. 13-30.

[6] C. Dziuban, P. Shea, and J. . Arbaugh, "Faculty Roles and Satisfaction in Asynchronous Learning Networks.” pp. 169-190, 2005.

[7] G. Cui and J. Hu, "Experimental Study to Develop Writing skills through Blended Learning in the Times of Internet+," MATEC Web Conf., vol. 246, 2018, doi: $10.1051 /$ matecconf/201824603031.

[8] B. Bray and K. McClaskey, "A step-by-step guide to personalize learning," Learn. Lead. with Technol., vol. 7, no. May, pp. 12-20, 2013.

[9] N. Vaughan, "Student engagement and blended learning: Making the assessment connection," Educ. Sci., vol. 4, no. 4, pp. 247-264, 2014, doi: 10.3390/educsci4040247.

[10] D. Adams, M. T. H. Joo, B. Sumintono, and O. S. Pei, "Blended learning engagement in higher education institutions: A differential item functioning analysis of students' backgrounds," Malaysian J. Learn. Instr., vol. 17, no. 1, pp. 133-158, 2020.

[11] R. Fisher, Á. Perényi, and N. Birdthistle, "The positive relationship between flipped and blended learning and student engagement, 
performance and satisfaction," Act. Learn. High. Educ., pp. 1-17, 2018, doi: $10.1177 / 1469787418801702$.

[12] G. Northey, T. Bucic, M. Chylinski, and R. Govind, "Increasing Student Engagement Using Asynchronous Learning," J. Mark. Educ., vol. 37, no. 3, pp. 1-10, 2015, doi: $10.1177 / 0273475315589814$.

[13] N. Pellas and I. Kazanidis, "On the value of Second Life for students' engagement in blended and online courses: A comparative study from the Higher Education in Greece," Educ. Inf. Technol., vol. 20, no. 3, pp. 445-466, 2015, doi: 10.1007/s10639-013-9294-4.

[14] M. Saritepeci and H. Çakir, "The Effect of Blended Learning Environments on Student's Academic Achievement and Student Engagement: A Study on Social Studies Course," Educ. Sci., vol. 40, no. 177, pp. 203216, 2015, doi: 10.15390/EB.2015.2592.

[15] R. Woods, J. D. Baker, and D. Hopper, "Hybrid structures: Faculty use and perception of webbased courseware as a supplement to face-toface instruction," Internet High. Educ., vol. 7, no. 4, pp. 281-297, 2004, doi: 10.1016/j.iheduc.2004.09.002.

[16] D. R. Garrison, T. Anderson, and W. Archer, "Critical thinking, cognitive presence, and computer conferencing in distance education," Am. J. Distance Educ., vol. 15, no. 1, pp. 7-23, 2001, doi: 10.1080/08923640109527071.

[17] P. Shea and T. Bidjerano, "Learning presence: Towards a theory of self-efficacy, selfregulation, and the development of a communities of inquiry in online and blended learning environments," Comput. Educ., 2010, doi: 10.1016/j.compedu.2010.07.017.

[18] W. Setyaningrum, "Self-regulated learning in blended learning approach," J. Phys. Conf. Ser., vol. 1320, no. 1, 2019, doi: 10.1088/17426596/1320/1/012089.

[19] J. Pool, G. Reitsma, and D. Van Den Berg, "Revised Community of Inquiry Framework: Examining Learning Presence in a Blended Mode of Delivery," vol. 21, no. 3, pp. 153-165, 2017, doi: 10.24059/olj.v.

[20] B. J. Zimmerman, "Becoming a self-regulated learner: An overview," Theory Pract., vol. 41, no. 2, pp. 64-70, 2002, doi: 10.1207/s15430421tip4102_2.

[21] P. Shea and T. Bidjerano, "Learning presence as a moderator in the community of inquiry model," Comput. Educ., vol. 59, no. 2, pp. 316326, 2012, doi:

10.1016/j.compedu.2012.01.011. 